\title{
Knowledge of Human Papillomavirus and its Incidence Among Women Referring to Al-Zahra and Taleghani Hospitals in Tabriz-Iran, 2014-2015
}

\author{
Jamileh Malakouti ${ }^{1}$, Mojgan Mirghafourvand ${ }^{2}$, Madineh Gorbani ${ }^{3}$, Hanieh Salehi Poormehr' ${ }^{2}$, Mehri Jafari \\ Shabiri ${ }^{4}$, Shakiba Pourasad Shahrak ${ }^{*}$
}

\begin{abstract}
Objectives: Human papillomavirus (HPV) is a common sexual transmitted disease throughout the world. It has been considered as the main cause of cervical cancer and second common cause of cervical cancer in 15-49 years old women. The aim of this study was to determine the Knowledge of HPV and its incidence among women referring to Al-Zahra and Taleghani hospitals in Tabriz-Iran, 2014-2015.

Materials and Methods: This cross-sectional study was conducted on 221 women aged 15-49 years old that were suspicious to HPV based on gynecologic examination and colposcopy. Data was collected using questionnaires consisted of two parts: sociodemographic information and knowledge of these women concerning HPV.

Results: The incidence rate of HPV among participants was 20.8\%. The mean (standard deviation) of knowledge score was 12.04 (3.9) from total scores of 0-20. There was no significant differences between participants with HPV and without HPV infection in terms of knowledge about HPV.

Conclusion: As women with HPV had low knowledge about this infection, therefore, health authorities should implement some interventions to enhance the knowledge of women about HPV infection in order to prevent its incidence and complications on women's health.

Key words: Human papilloma virus, Cervical cancer, Knowledge
\end{abstract}

\section{Introduction}

Cervical cancer is the most common cancer among women. One of the main cause of this cancer is human papillomavirus (HPV) (1). Since the main risk factor for development of cervical cancer is the types of 16 and 18 HPV (2), so the knowledge of women, vaccination against it as well as conducting of Pap smear protect women from getting cervical cancer (3). Although screening for precancerous lesions such as Pap smear could reduce the incidence and mortality from cervical cancer (4), unlike developed countries, cervical cancer prevention programs have failed to meet objectives in developing countries due to the financial, social and cultural problems $(5,6)$.

The prevalence rate of HPV was reported between $10 \%-24.4 \%$ in different studies $(7,8)$. Despite the high prevalence of HPV infection among young women, studies in Western countries have shown that most adolescent and young women have poor information regarding the HPV infection $(9,10)$.

The relationship between HPV and cervical cancer is most well-known. However, the basic issues regarding the causes of cervical cancer has been not completely trained among young women at our society. Thus, such issues regarding the causes of cervical cancer, and information of HPV should be thought to women. It seems be a need to this health issue and should be completely realized even though by the medical community too (11). This could be a reasonable explain why knowledge and understanding of women and among the general public regarding HPV is so low that unlikely are confused about HPV (12). The purpose of current study was assessing the knowledge of women about HPV and the incidence rate of this infection among participants.

\section{Materials and Methods}

This cross-sectional study was done on 221 women in AL-Zahra and Taleghani therapeutic educational centers, Tabriz-Iran in 2014-2015. Sample size was determined 221, considering $P=0.17, \mathrm{q}=0.83, \mathrm{CI}=95 \%, \mathrm{~d}=0.05$ based on the study of Leyh-Bannurah et al (13). Sampling method was convenience. Married women aged 15-49 years old with symptoms of resistant vaginal discharge and itching, vaginal irritation, dyspareunia or HPV wart on perineum were chosen for aim of this study. The objectives and methods of conducting study were explained to women and in terms of their willingness to participate, a written 
informed consent was completed and signed by them at the time of study enrollment.

The data collection tool included the questionnaires of socio-demographic characteristics and knowledge about HPV. Socio-demographic characteristics were consisted of age, education and job of women and their spouses, marital status and income efficiency items. The knowledge questionnaire was developed by the research team. It was consisted of knowledge about HPV contamination ways, role of condom in its prevention of HPV, symptoms of HPV, relationship between HPV and cervical cancer, HPV prevention items. The content and face validity was used to confirm the scientific validity of socio-demographic and knowledge questionnaires. For this purpose, the questionnaires were given to 10 academic members of Tabriz University of Medical Sciences to evaluate the content of questionnaire. After obtaining their ideas, required changes were checked and corrected, then it was used for study purposes. The knowledge questionnaire has been used already in same study environment on women referring to health centers of Tabriz and ICC (intraclass correlation coefficient) was reported 0.82 according to the study of Farshbaf-Khalili et al (14).

The questionnaire was given to participants in a private place and asked them to answer questions. After completing the questionnaire, women were asked to lie on the lithotomic position and colposcopy was done by a female Onco-Gynecologist. In women with suspicious lesions, biopsy was carried out by the same gynecologist and the samples of biopsies were sent to the laboratory in order to be evaluated by the pathologist and the results were reported to us.

Data were analyzed through SPSS version 13 . The statistical tests such as $t$ test and chi-square were used for data analysis. In this study, $P$ value less than 0.05 were considered to be significant.

\section{Results}

Mean (SD) age of participants were 37.3 (9.6). A total of $186(84.2 \%)$ of women were housewives and $32.1 \%$ of their husbands were businessmen (Table 1).

According to both methods of screening: colposcopy and biopsy, 46 (20.8\%) of participants were infected by HPV In this research (Table 2 ).

The mean (SD) level of knowledge score was 12.04 (3.9) from total scores of 0-20. There was no statistically significant difference among participants with HPV or without HPV infection in terms of knowledge score $(P=0.936)$. The mean (SD) of knowledge among women with HPV positive and HPV negative was 12.1 (4.1) and 12.0 (3.9), respectively (Table 3).

According to Table 4, most of participants did not have any information about HPV infection, 16 (14.5\%) in HPV positive group and 94 (85.7\%) in HPV negative group. The source of getting information by the most of participant's in HPV positive and negative groups was by travelling to the other countries. The role of book was lower than other information sources. There were no statistically significant
Table 1. Sociodemographic Characteristics in Participants $(n=221)$

\begin{tabular}{|c|c|}
\hline Variables & No. (\%) \\
\hline Age $(y)^{a}$ & $37.3(9.6)$ \\
\hline \multicolumn{2}{|l|}{ Women Education } \\
\hline Illiterate & $7(3.2)$ \\
\hline Elementary & $90(40.8)$ \\
\hline High school & $75(34.0)$ \\
\hline University & $49(22.2)$ \\
\hline \multicolumn{2}{|l|}{ Marriage status } \\
\hline Having husband & 212 (95.9) \\
\hline Widows & $9(4.1)$ \\
\hline \multicolumn{2}{|l|}{ Husband education } \\
\hline Illiterate & $3(1.4)$ \\
\hline Elementary & $95(43.0)$ \\
\hline High school & $59(26.7)$ \\
\hline University & 55 (24.9) \\
\hline \multicolumn{2}{|l|}{ Women job } \\
\hline Housewife & $186(84.2)$ \\
\hline Work at home & $10(4.5)$ \\
\hline Work out of home & $25(11.3)$ \\
\hline \multicolumn{2}{|l|}{ Husband job } \\
\hline Without job & $2(0.9)$ \\
\hline Employee & $45(20.4)$ \\
\hline Clerk & $62(28.1)$ \\
\hline Businessman & $71(32.1)$ \\
\hline Manager & $15(6.8)$ \\
\hline \multicolumn{2}{|l|}{ Income efficiency } \\
\hline Sufficient & 39 (17.6) \\
\hline Almost sufficient & $113(51.5)$ \\
\hline Not sufficient & $69(31.2)$ \\
\hline
\end{tabular}

Table 2. Human Papillomavirus Prevalence in Participant $(n=221)$

\begin{tabular}{lc}
\hline Variables & $\mathrm{N}(\%)$ \\
\hline HPV positive ${ }^{\mathrm{a}}$ & $46(20.8)$ \\
HPV negative & $175(79.2)$ \\
\hline${ }^{a}$ According to biopsy &
\end{tabular}

Table 3. Knowledge About Human Papillomavirus Infection Among Participants $(n=221)$

\begin{tabular}{lccc}
\hline Knowledge & $\begin{array}{c}\text { HPV Positive } \\
\text { No. (\%) }\end{array}$ & $\begin{array}{c}\text { HPV Negative } \\
\text { No. (\%) }\end{array}$ & P \\
\hline Low & $26(56.5)$ & $109(62.3)$ & \\
Moderate & $14(30.4)$ & $56(32.0)$ & $0.231^{\text {a }}$ \\
High & $6(13.0)$ & $10(5.7)$ & \\
Mean (SD) & $12.1(4.1)$ & $12.0(3.9)$ & $0.936^{\mathrm{b}}$ \\
\hline a Chi-Square test. & & & \\
${ }^{\mathrm{b}} T$ test. & & &
\end{tabular}

differences between HPV positive and negative groups in terms of information scores $(P=0.118)$.

\section{Discussion}

In this cross-sectional research, most of women had low level of knowledge about HPV and its transmission ways, but with the higher incidence of HPV (20.8\%). Despite the high incidence of HPV in our setting, the level of knowledge about its prevention ways was low. 
Table 4. Source of Getting Information About Human Papillomavirus Infection Among Participants $(n=221$ )

\begin{tabular}{lll}
\hline \multirow{2}{*}{ Source of Information } & $\begin{array}{l}\text { HPV Positive } \\
\text { No. (\%) }\end{array}$ & $\begin{array}{l}\text { HPV Negative } \\
\text { No. (\%) }\end{array}$ \\
\hline Media & $2(14.3)$ & $12(58.7)$ \\
Health system & $3(27.3)$ & $8(72.7)$ \\
Friends & $2(20.0)$ & $8(80.0)$ \\
Book & $0(0.0)$ & $4(100.0)$ \\
Net & $9(37.5)$ & $15(62.5)$ \\
Doctor's official & $1(14.3)$ & $6(85.7)$ \\
Other sources & $13(31.7)$ & $28(68.3)$ \\
No information & $16(14.5)$ & $94(85.5)$ \\
\hline
\end{tabular}

${ }^{\mathrm{a}} P=0.118$

The results of a study done by Siddharthar et al showed that Less than one-fourth of the population knew about screening services for prevention of cervical cancer, and majority of participants $(389,97.2 \%)$ were not aware of vaccination as prevention way of cervical cancer. They mentioned that only $6.5 \%$ of participants had heard about HPV infection as a risk factor of cervical cancer and only $2.8 \%$ of them knew about HPV vaccination (15). In a study conducted in China by Hong et al, $22.1 \%$ and $13.3 \%$ of population had some information about HPV and its vaccine, respectively (16). Marlow et al showed that only $47 \%$ of population had information about HPV and their level of knowledge score was 7.5 from 11 (17). Results of a study was done in Turkey by Kurt et al among medical students showed that $55 \%$ of students had enough knowledge about HPV vaccine (18).

In our research, $13 \%$ of women in HPV positive group and $5.7 \%$ of women in HPV negative group had sufficient knowledge about this infection and its transmission ways; also, $56.5 \%$ of participants in HPV positive group and $62.3 \%$ of participants in HPV negative group had low level of knowledge about it.

In Iran, 25.61 million women aged 15 years old and older are at risk of cervical cancer as the second cause of death with low or poor level of knowledge about HPV (19). HPV vaccine named Gardasil is available to prevent HPV infection and cervical cancer (2). Australia was the first country that used HPV vaccine in their health system for prevention of this infection (20). While the Gardasil vaccine is available in Iran, low people know about its advantages; for example, in our research 28 women (12.7\%) mentioned the availability of HPV vaccine in Iran, but the main fact is that even our people know about HPV vaccine but unfortunately they could not use it because of its high price.

Although, the mass media is the most important source to inform people, in our survey, only 14 (6.3\%) of participants mentioned they got their information from media. In the study done by Siddharthar et al at India in 2014, 17\% of participants mentioned that the main source of their information was their neighbors and the role of media was $16.3 \%$ (15). Different studies showed that educated \& employed women have more information about HPV (15, 21). While, other studies showed that even high educated women have low level of HPV knowledge too $(22,23)$. This study was carried out on women at reproductive age in Tabriz-Iran. It is recommended other studies to be performed with large sample size in different geographic places of Iran among male and other ethnic groups. The limitation of this study was in relation to its small sample size.

\section{Conclusion}

The findings of our research show that as women had low level of knowledge about HPV infection and its transition ways, therefore, health authorities should implement some interventions to enhance the knowledge of women about HPV infection in order to prevent its incidence and complications on women's health.

\section{Ethical Issues}

This study was conducted on women referring to ALZahra and Taleghani hospitals in Tabriz-Iran after receiving permission from the Ethics Committee of Tabriz University of Medical Sciences (code of ethics: 5023/4/5).

\section{Conflict of Interest}

The authors declare no conflict of interest.

\section{Financial Support}

This study was supported by Women's Reproductive Health Research Center of Al-Zahra hospital, Tabriz University of Medical Sciences.

\section{Acknowledgments}

The researchers appreciate the staff of the Research Committee, personnel of Al-Zahra and Taleghani hospitals and all women who participated in this study.

\section{References}

1. Trottier H, Franco EL. The epidemiology of genital human papillomavirus infection. Vaccine. 2006;24(Suppl 1):1-15.

2. Bosch FX, de Sanjosé SS. Human papillomavirus and cervical cancer - burden and assessment of causality. J Natl Cancer Inst Monogr. 2003;31:3-13.

3. Singhal T. Indian Academy of Pediatrics Committee on Immunisation (IAPCOI)- Consensus Recommendations on Immunization. Indian Pediatr. 2008;45:635-648.

4. Miller AB, Chamberlain J, Day NE, Hakama M, Prorok PC. Report on a workshop of the UICC project on evaluation of screening for cancer. Int J Cancer. 1990;46:761-769.

5. Lazcano-Ponce EC, Moss S, Alonso DR, Salmeron CJ, Hernandez AM. Cervical cancer screening in developing countries: why is it ineffective? The case of Mexico. Arch Med Res. 1999;30:240-250.

6. Sankaranarayanan R, Budukh AM, Rajkumar R. Effective screening programmes for cervical cancer in low- and middle-income developing countries. Bull World Health Organ. 2001;79:954-962.

7. Clifford GM, Gallus S, Herrero R, et al. Worldwide distribution of human papillomavirus types in cytologically normal women in the International Agency for Research on Cancer HPV prevalence surveys: a pooled analysis. Lancet. 2005;366(9490):991-998. 
8. de Sanjosé S, Diaz M, Castellsagué X, et al. Worldwide prevalence and genotype distribution of cervical human papillomavirus DNA in women with normal cytology: a meta-analysis. Infect Dis Lancet. 2007;7(7):453-459.

9. Giles M, Garland S. A study of women's knowledge regarding human papillomavirus infection, cervical cancer and human papillomavirus vaccines. Aust NZ J Obstet Gynaecol. 2006;46(4):311-315.

10. Dell DL, Chen H, Ahmad F. Knowledge about human papillomavirus among adolescents. Obstet Gynecol. 2000;96:653-656.

11. Howard M, Koteles J, Lytwyn A, Elit L, Kaczorowski J, Randazzo J. Giving patients information on abnormal cytology and human papillomavirus: survey of health providers. Eur J Gynaecol Oncol. 2007;28:15-17.

12. Fernbach M. Young women's issues associated with Pap tests: a qualitative study of Victorian women. Health Promot J Aust. 2001;12:254-257.

13. Leyh-Bannurah S, Prugger C, de Koning MN, Goette $\mathrm{H}$, Lellé RJ. Cervical human papillomavirus prevalence and genotype distribution among hybrid capture 2 positive women 15 to 64 years of age in the Gurage zone, rural Ethiopia. Infect Agent Cancer. 2014;9(1):33. doi: 10.1186/1750-9378-9-33.

14. Farshbaf-khalili A, Shahnazi M, Salehi-pourmehr $\mathrm{H}$, Faridvand F. Behavioral prevention regarding sexually transmitted infections and its predictors in women. Iran Red Crescent Med J. 2014;16(8):18346.

15. Siddharthar J, Rajkumar B, Deivasigamani K. Knowledge, awareness and prevention of cervical cancer among women attending a tertiary care hospital in puducherry, India. J Clin Diagn Res. 2014;8(6):OC01-3. doi:10.7860/ JCDR/2014/8115.4422.
16. Hong Y, Zhang C, Li X, Lin D, Liu Y. HPV and cervical cancer related knowledge, awareness and testing behaviors in a community sample of female sex workers in China. BMC Public Health. 2013;13:696. doi:10.1186/1471-245813-696.

17. Marlow LA, Waller J, Wardle J. Public awareness that HPV is a risk factor for cervical cancer. Br J Cancer. 2007;97:691694.

18. Kurt KR, Karateke A, Erdem A, Silfeler BD, Akkoca NA, Hakverdi UA. Human Papilloma virus and HPV vaccine knowledge among Mustafa Kemal University Medical Students. Acta Medica Anatolia. 2014;2(2):37-41.

19. WHO. Human papillomavirus (HPV) and cervical cancer. http://www.who.int/mediacentre/factsheets/fs380/en/. Accessed Aug 23, 2014.

20. Brotherton JML, Kaldor JM, Garland SM. Monitoring the control of human papillomavirus (HPV) infection and related diseases in Australia: towards a national HPV surveillance strategy. Sex Health. 2010;7:310-319.

21. Jia Y, Li S, Yang R, Zhou H, Xiang Q, Hu T. Knowledge about cervical cancer and barriers of screening program among women in wufeng county, a high-incidence region of cervical cancer in China. PLoS One. 2013;8(7):e67005. doi:10.1371/journal.pone.0067005.

22. Waller J, Mc Caffery KJ, Forrest S, Wardle J. Human papillomavirus and cervical cancer: issues for biobehavioral and psychosocial research. Ann Behav Med. 2004;27:68-79.

23. Goldsmith MR, Bankhead CR, Kehoes ST, Marsh G, Austoker J. Information and cervical screening: a qualitative study of women's awareness, understanding and information needs about HPV. J Med Screen. 2007;14:2933.

Copyright (c) 2017 The Author (s); This is an open-access article distributed under the terms of the Creative Commons Attribution License (http://creativecommons.org/licenses/by/4.0), which permits unrestricted use, distribution, and reproduction in any medium, provided the original work is properly cited. 